\title{
Razón práctica e intelecto agente en Alfarabi
}

\author{
Rafael Ramón Guerrero \\ Universidad Complutense
}

In this article I seek to show how, for Alfarabi, the agent intellect is not only giver of cognitive forms for the theoretical reason, but rather it also endow to the practical reason with "voluntary intelligibles". Later, the first practical principles can be used as foundation in order to construct the ethics as demonstrative science.

En un número anterior de esta misma Revista, el Dr. J. A. Garcia Cuadrado $^{1}$ invoca el carácter central que la doctrina del intelecto agente tiene en Aristóteles, como entendieron comentadores griegos, árabes, judios y cristianos, y señala cómo los estudiosos de la doctrina aristotélica reconocen la importancia y función del intelecto agente respecto del conocimiento teórico, olvidando "su conexión con la razón práctica y con el obrar humano"2. Tras evocar las distintas funciones que la tradición ha asignado al intelecto agente, vuelve a recordar que ellas no aluden para nada a la dimensión práctica del conocimiento. El Dr. García Cuadrado se aplica seguidamente a la sindéresis en Santo Tomás, esto es, al hábito de los primeros principios en el orden práctico, cuyo conocimiento compete también al intelecto, del que ya se habia ocupado José A. Garcia-Junceda $^{3}$. Después, el Dr. García Cuadrado apunta que el intelecto agente actúa también sobre los singulares, para mostrar lo cual hace un estudio de la estimativa animal y de la cogitativa

\footnotetext{
1 "Entendimiento agente y razón práctica", en Tópicos 16 (1999), pp. 39-58.

2 "Entendimiento agente..., p. 43.

${ }^{3}$ La sindéresis en el pensamiento de Santo Tomás, Madrid, 1962.
} 
humana, y concluye que es la actualización de ésta por el intelecto agente la que realiza una triple tarea: formar silogismos particulares, captar de manera accidental la sustancia individual y dirigir la acción práctica de la voluntad ${ }^{4}$.

En sintonia con este preciso trabajo del Dr. García Cuadrado, quiero aquí mostrar cómo Alfarabi ya había tenido en cuenta que la acción del intelecto agente se ejerce también sobre la razón práctica del hombre: da lugar a silogismos particulares, dirige la acción humana y permite fundar una ciencia demostrativa basada en los primeros principios prácticos: la ética.

\section{Los intelectos de Alfarabi}

La cuestión del intelecto parte de los origenes mismos del filosofar en Grecia. Heráclito, Parménides y Platón son los hitos que configuraron la primera historia de este problema. Pero el De anima de Aristóteles delimitó el ámbito en el que habría de plantearse la cuestión del intelecto ${ }^{5}$, si bien lo hizo de una manera tan problemática que la historia posterior de ella no es sino el intento de esclarecer los términos en que Aristóteles la situó: las condiciones de posibilidad del conocimiento humano estaban definidas por el intelecto capaz de hacerse todas las cosas ( $\pi \alpha v \tau \alpha \gamma$ ' $\gamma \nu \varepsilon \sigma \theta \alpha \mathrm{l})$ y por el intelecto capaz de hacer todas las cosas $(\pi \alpha \nu \tau \alpha \pi \text { olei } \nu)^{6}$. Determinar la naturaleza de este segundo intelecto, llamado con

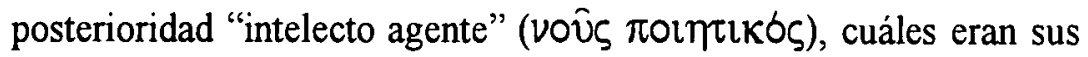
funciones y cómo hacía posible el conocer humano, fueron las tareas a las que se entregó la filosofia posterior. Desde Teofrasto hasta los últimos comentadores griegos de Alejandría, el problema del intelecto fue pensado y recibió distintas soluciones. Los árabes, después de entrar en contacto con la filosofia griega, lo recibió en herencia y lo convirtió en eje sobre el que giró todo el pensamiento

\footnotetext{
4 "Entendimiento agente..., pp. 57-58.

5 No hay que olvidar los otros textos en que el Estagirita habla del intelecto, como luego vería Alfarabi. Pero, sin duda, la obra desde la que principalmente se estableció el intelecto como problema fue el De anima.

${ }^{6}$ ARISTÓTEles: De anima, III, 5, 430a 14-15.
} 
filosófico que elaboraron, siendo punto nuclear y explicativo de todo él?.

Los dos intelectos del De anima de Aristóteles se han convertido en Alkindi en cuatro:

"La opinión de Aristóteles acerca del intelecto es que éste es de cuatro clases. La primera de ellas es el intelecto que está en acto siempre; la segunda es el intelecto que está en potencia y pertenece al alma; la tercera es el intelecto que ha pasado en el alma de la potencia al acto; la cuarta es el intelecto que llamamos segundo"8.

El primero es el intelecto agente, al que ya se hace independiente del hombre. El segundo es el intelecto que está en potencia, aquel que es capaz de devenir todas las cosas. El tercero es el intelecto que ha pasado de la potencia al acto, puesto que ya ha recibido formas inteligibles, y que ha alcanzado la condición de habitual: es como el escribiente, que domina el arte de la escritura, pero cuando no está escribiendo. El cuarto y último no es más que un segundo momento ${ }^{9}$ de este tercer intelecto: es su manifestación, su exteriorización, su realización dinámica, su perfección definitiva; es el escribiente en tanto que es escribiente: cuando está escribiendo ${ }^{10}$.

Alfarabi ha escrito una Epistola sobre la esencia del alma en la que sostiene que el alma racional está separada del cuerpo por su acción, por la sabiduría y por el pensamiento; sólo se une a la materia de manera externa, puesto que su fin es unirse al mundo superior por medio del intelecto; encuentra su término en el intelecto

${ }^{7}$ Puede verse la amplia bibliografia que García Cuadrado cita en sus notas 8, 9 y 10. ${ }^{8}$ Risâla fi l-'aql, M. ABU RIDA (ed.): Rasấil al-Kindî al-falsafiyya, El Cairo, vol. I, 1950, pp. 353-354; trad. esp.: R. Ramón Guerrero-E. Tornero Poveda: Obras filosóficas de al-Kindi, Madrid: Coloquio 1986, p. 150.

9 Por eso habla del "intelecto que llamamos segundo".

$10 \mathrm{Cfr}$. R. Ramón Guerrero: La recepción árabe del 'De anima' de Aristóteles. AlKindi y al-Farabi, Madrid: CSIC 1992, pp. 135-149. 
agente $^{11}$. Así, el alma racional es el vínculo de unión entre el mundo superior, que emana del Ser primero, y el mundo sublunar, cuyo origen inmediato está en el intelecto agente como último intelecto separado. El alma es el punto de encuentro de dos procesos, el descendente desde el Uno y el ascendente a través del movimiento provocado por el amor. Esto pone de manifiesto la importancia de la facultad superior del hombre: articula la metafisica, ontología, cosmología, antropología, psicología y ética y política del pensamiento filosófico alfarabiano. Puesto que la operación propia de esta alma racional está desligada de la materia y puesto que, a diferencia de las otras almas, su propia operación constituye su propia perfección, Alfarabi ha de estudiar con detenimiento la naturaleza de esta facultad, que es aquella "por la que el hombre entiende, reflexiona, adquiere las ciencias y las artes y por la que distingue lo hermoso y lo censurable de las acciones", según la define en sus Artículos de la ciencia política ${ }^{12}$.

En Las fuentes de las cuestiones ${ }^{13}$ ha establecido una primera división de la facultad racional, fundada en De anima III, 10, 433a, y en otros textos aristotélicos:

"Entre estas facultades del alma están el intelecto práctico, que es aquel que descubre qué acciones humanas se deben hacer, $y$ el intelecto especulativo, que es aquel con el que se perfecciona la substancia del alma y se convierte en substancia intelectual en acto: Hay diversos grados de este intelecto, pues unas veces es intelecto material, otras veces intelecto en hábito $\mathrm{y}$ otras veces intelecto adquirido. Estas facultades, que aprehenden las formas inteligibles, son una

11 E. Bertola: "La dottrina psicologica di al-Fârâbî: Il Trattato sulla natura dell'anima", en Archivio di Filosofia, 55 (1987) pp. 405-440.

${ }^{12}$ Fusûl muntaza'ah (Selected Aphorisms), Arabic text, edited with an introduction and notes by F. M. Najjar, Beirut: Dar el-Machreq, 1971, \$70, p. 29; trad. esp.: ALFÂRÂBİ: Obras filosófico-politicas, R. RAMÓN GUERRERO (ed.), Madrid: DebateCSIC 1992, p. 101

13 'Uyin al-masâ'il, F. DIETERICI (ed.): Al-Fârâbî's philosophische Abhandlungen, Leiden: J. Brill 1890, pp. 56-65; trad. esp.: M. Alonso: "Los 'Uyûn al-masâ'il de al-Fârâbî", en Al-Andalus, 24 (1959), pp. 251-273. 
substancia simple e incorpórea, y no pasa de la potencia al acto ni se convierte en intelecto perfecto a no ser por medio de un intelecto separado, que es el intelecto agente, que la reduce de la potencia al acto. Las formas inteligibles no pueden estar contenidas en algo dotado de partes o de lugar. Es una substancia separada de la materia, que permanece después de la muerte del cuerpo, pues no tiene capacidad para corromperse. Es una substancia única: tal es en realidad el hombre, aunque tenga facultades esparcidas por los miembros"14.

Así, la perfección del alma procede del intelecto, un término que, por aparecer en diversos contextos, ofrece varias significaciones. Para dilucidar estas acepciones que tiene, Alfarabi compuso su Epistola sobre los significados del intelecto ${ }^{15}$, conocida en el mundo latino medieval con los títulos De intellectu o De intellectu et intelligibili ${ }^{16}$. Se inicia con una constatación de cómo el término "intelecto"17 suele ser usado con diversos sentidos:

14 'Uyîn al-masâ'il, F. Dietericl (ed.): Al-Fârâbî's..., p. 64; trad. esp.: M. ALONso: "Los 'Uyün al-masâ'il..., pp. 271-272.

15 Hay dos ediciones de este opúsculo farabiano: 'Uyûn al-masâ'il, F. DIETERICI (ed.): Al-Fârâbî's..., pp. 39-48. AL-FÂRÂBî: Risâla fí ma'ânî l-'aql, M. Bouyges (ed.), Beirut: Imprimerie Catholique 1938. Traducciones: alemana, F. DETTERICl: $A l$ Fârâbî's philosophische Abhandlungen aus dem arabischen Übersetzt, Leiden: J. Brill 1892; italiana, F. LuccheTTA: Farabi. Epistola sull'intelletto, Padova: Antenore 1974; española: R. Ramón GUERRERO: Contribución a la historia de la filosofia árabe: Alma e intelecto como problemas fundamentales de la misma, Madrid: Ed. de la Universidad Complutense 1981, pp. 397- 463.

${ }^{16} \mathrm{G}$. CAMERARIUS (ed.): Alpharabii vetustissimi Aristotelis interpretis opera quae latina lingua conscripta reperiri potuerunt, Parisii: apud Dionysium Moreau 1683. Reimpresión, Frankfurt am Main: Minerva 1969. E. GILson: "Les sources grécoarabes de l'augustinisme avicennisant", en Archives d'Histoire Doctrinale et Litteraire du Moyen Age, 4 (1929), pp. 124-141.

${ }^{17}$ En las traducciones latinas, el término árabe 'aql, que traduce el voūs griego, es vertido unas veces por intellectus y otras por intelligentia. Este desdoblamiento que la Edad Media latina introdujo sobre un mismo término griego y árabe tuvo como objeto distinguir entre el intelecto humano (intellectus) y las substancias separadas, motores de las esferas celestes (intelligentia), cfr. J. JOLIVET: "Intellect et intelligence. Note sur la tradition arabo-latine des $12^{\circ}$ et $13^{\mathrm{e}}$ siècles", en Mélanges 
"El nombre de 'intelecto' se dice de muchas maneras: 1) Aquello por lo que el vulgo dice de un hombre que es inteligente. 2) El intelecto que los teólogos usan constantemente de manera habitual, cuando dicen: 'esto es lo que el intelecto exige' o 'esto es lo que el intelecto rechaza'. 3) El intelecto que el maestro Aristóteles cita en el Libro de la demostración. 4) El intelecto que cita en el tratado sexto del Libro de la ética. 5) El intelecto que cita en el Libro del alma. 6) El intelecto que cita en el Libro de la metafisica"18.

A continuación, Alfarabi se entrega al estudio de cada uno de estos seis significados ${ }^{19}$.

\section{El intelecto agente y sus funciones.}

En su obra Politica ${ }^{20}$, Alfarabi afirma que hay seis principios, de los cuales el tercero es el intelecto agente ( $a l$ - 'aql $a l-f a$ ' $a l)$, siendo los dos primeros la Causa primera y las causas segundas; ninguno de estos tres principios son cuerpos ni están en cuerpos. ¿Qué quiere decir esto?

Para entenderlo hay que conocer la estructuración que Alfarabi hace del universo según un modelo neoplatónico matizado con doctrinas aristotélicas. Partiendo de la distinción entre ser necesario y ser posible, Alfarabi modifica, como consecuencia de la teoría de la creación afirmada en el Islam, la metafisica aristotélica, al explicar el cambio como la recepción de la existencia por parte de una esencia: lo que no es, el ser meramente posible, se convierte en existente cuando recibe una existencia. ¿De dónde le viene ésta?

offerts à Henry Corbin, S. H. NASR (ed.), Teherán: Institute of Islamic Studies 1977, pp. 681-702.

18 Ed. Bouyges, pp. 3-4.

19 Un análisis de estos diversos significados puede verse en mi obra citada $L a$ recepción árabe del 'De anima', pp. 180-207.

20 Al-Fârâbî's The political Regime (Al-siyâsa al-madaniyya also known as the Treatise on the Principles of Beings), Arabic text, edited with an Introduction and notes by F. M. NAJJAR, Beirut: Imprimerie Catholique 1964, p. 31; trad. esp.: ALFÂRÂBÎ: Obras filosófico-politicas..., p. 5. 
Sólo puede proceder de un ser en el que esencia y existencia se identifiquen. Tal es el Ser Necesario, al que Alfarabi caracteriza como el Ser Primero, la Causa Primera de todas las cosas, el Uno, perfecto, autosuficiente, incausado, inmóvil, inmaterial, sin contrario y no susceptible de ser definido, según se lee en La ciudad excelente $^{21}$. Y este Ser es el Dios de la religión, pues de Él "se debe creer que es Dios y la causa próxima de la existencia de las causas segundas y del intelecto agente"22.

El Ser Primero ocupa el vértice de la totalidad de lo real, coincide con el Uno de Plotino y con la Unicidad divina afirmada en el Corán. Pero, además, posee un rasgo que le distingue con toda nitidez de la Unidad plotiniana. Es, también, la Razón, el Noûs del que Aristóteles habla en el libro XII de Metafisica, cuya ocupación es pensarse a sí mismo. Así lo identifica en la Epístola, en el sexto de los sentidos que Alfarabi distingue en el término "intelecto"23. El Uno plotiniano supera toda inteligibilidad, mientras que el Uno alfarabiano "entiende su propia esencia y por entender su esencia es inteligente e intelecto en acto" 24 . Este pensarse a sí mismo es el que genera la multiplicidad en un proceso que sigue el esquema neoplatónico de la procesión de los seres, dando lugar a una gradación ontológica de seres, en los que los superiores son más perfectos en cuanto al ser que los inferiores.

Del Ser Primero emana el primer intelecto, al pensarse aquél como intelecto. Siendo uno también, este primer ser emanado contiene ya

21 Kitâb mabâdi ્̧y ârâ ahl al-madina al-fâdila, R. WALZER (ed.), Oxford: Clarendon Press 1985, pp. 56-101; trad. esp.: M. ALONSO: "El 'Al-Madîna al-fâdila" de al-Fârâbî", en Al-Andalus, 26 (1961), pp. 337-388 y 27 (1962), pp. 181-227; reproducida, con presentación de $\mathrm{M}$. Cruz Hernández, Madrid: Tecnos 1985 pp. 327. Al-Fârâbî's The political Regime (Al-siyâsa.., pp. 42-52; trad. esp.: AL-FÂRÂBî: Obras filosófico-politicas..., pp. 17-24.

22 Al-Fârâbî's The political Regime (Al-siyâsa..., p. 31; trad. esp.: AL-FÂrÂBî: Obras filosófico-politicas..., p. 6.

23 AL-FÂRÂBî: Risâla fî ma'ânî..., pp. 35-36; trad. esp. R. Ramón GUERRERO: Contribución a la historia de la filosofia árabe..., pp. 461-463.

${ }^{24}$ Kitâb mabâdi 5 ârâ ahl al-madina al-fâdila..., p. 70; trad. esp. M. Alonso: "El Al-Madîna al-fầdila' de al-Fârâbî"..., p. 13. 
la pluralidad, puesto que puede pensarse a si mismo como distinto del Ser primero, por una parte, y puede pensar al Ser Primero del que procede, por otra. De él surge un segundo intelecto y la esfera del primer cielo. A su vez, de este segundo intelecto emanado y por el mismo procedimiento de naturaleza estrictamente intelectual, brota un tercer intelecto y una segunda esfera, la de las estrellas fijas. Prosigue la emanación de seres en una procesión decreciente y necesaria, hasta llegar al décimo intelecto y a la novena esfera, la de la luna, en que finaliza el universo superior ${ }^{25}$.

El décimo intelecto es conocido por el nombre de intelecto agente, que atiende la región sublunar, constituida por el mundo de la generación y de la corrupción, esto es, por la tierra. Un mundo constituido por los cuatro elementos, que proceden de la materia, informada por ese intelecto, cuya tarea específica es la de dar formas, por lo que ha sido llamado el "Dador de formas" (wâhib alsuwar, dator formarum ${ }^{26}$ : ónticas para la constitución de los seres del mundo sublunar y noéticas para actualizar la capacidad cognoscitiva del hombre.

En la Política, Alfarabi expone con claridad cuál es la función principal de este intelecto agente: "ocuparse del animal racional y procurar que alcance el más elevado grado de perfección que le cabe lograr al hombre: la felicidad suprema; es decir, hacer que el hombre llegue al grado del intelecto agente" 27 . Tiene que ver, pues, con la felicidad humana.

La estructura del hombre es semejante a la del universo. Dos mundos, uno sensible y sometido a la generación y corrupción, el cuerpo; y otro de naturaleza superior, separable del cuerpo y de origen divino, el alma y su facultad intelectual. A través de ésta, el hombre puede alcanzar su perfección, haciéndose semejante al

${ }^{25}$ Madîna al-fâdila, pp. 100-104; trad., pp. 28-30.

26 'Uyûn al-masâ'il..., p. 64; trad. esp.: M. Alonso: "Los 'Uyûn al-masâ'il..., p. 272.

27 Al-Fârâbî's The political Regime (Al-siyâsa..., p. 32; trad. esp.: AL-FÂRÂBî: Obras filosófico-politicas..., p. 7. 
intelecto agente, que cumple en este proceso un oficio similar al del Ser Primero respecto al universo. Conocer es asimilar las formas inteligibles, por lo que le interesa el proceso por el que el inteligible pasa del estado de potencia al de inteligible en acto. El movimiento para unirse con el intelecto agente, en que consiste la felicidad, se inicia con el intelecto en potencia o "material"; cuando entra en contacto con las formas inteligibles, se actualiza y se convierte en intelecto en acto, para lo cual es necesario que los inteligibles en potencia, que informan las cosas materiales, se hagan inteligibles en acto. Actualizado el intelecto y producida la identificación entre formas inteligibles e intelecto, la facultad humana es capaz de realizar una operación más elevada: puede volverse sobre sí misma y conocer las formas inteligibles que ya posee; se piensa como intelecto en acto y se perfecciona, llegando a ser intelecto adquirido. $\mathrm{Y}$ al conocer sus propios contenidos en acto, este intelecto crea la posibilidad de adquirir las formas separadas, las formas inmateriales subsistentes por si en el mundo supralunar. Pensarlas es posible porque su ser es semejante al ser de las formas inteligibles ya pensadas. Por esta semejanza, las formas puras pueden ser conocidas en un acto de intuición intelectual, sin relación con lo sensible. El intelecto adquirido es, así, la perfección del intelecto humano, puesto que permite la unión con las substancias separadas y pone al hombre en relación con el mundo superior ${ }^{28}$.

Pero para que todo el proceso de actualización $y$ perfeccionamiento del intelecto humano sea posible es necesaria la intervención del intelecto agente, causa de la inteligibilidad y de la intelección del intelecto humano. Es un intelecto en acto, forma separada e inmaterial, que hace intelecto en acto al intelecto en potencia e inteligibles en acto a los inteligibles en potencia, siendo su relación al intelecto que está en potencia como la relación del sol al ojo, que es vista en potencia mientras no está iluminado por el $\mathrm{sol}^{29}$. Alcanzar ese perfeccionamiento significa obtener la felicidad.

28 Cfr. AL-F ÂRÂBî̀: Risâla fi ma'ânî..., pp. 15-22; trad. esp. R. Ramón GUERRERo: Contribución a la historia de la filosofia árabe..., pp. $421-435$.

29 AL-FÂRÀBî̀: Risâla fî ma'ânî..., pp. 24-25; trad. esp. R. Ramón GUERRERo: Contribución a la historia de la filosofia árabe..., pp. 439-441. 
Alfarabi reconoció explícitamente el deseo vehemente que todo hombre siente por adquirir la felicidad:

"La felicidad es un fin que todo hombre desea. Todo aquel que se dirige con su esfuerzo hacia ella, tiende a ella sólo en tanto que es una cierta perfección. $Y$ esto es algo que no necesita ser explicado por medio de razón alguna, porque es sumamente conocido: toda perfección es un fin que el hombre desea" 30 .

Insiste en que la felicidad es el fin último al que tiende todo hombre:

"Puesto que el objetivo de la existencia del hombre está en alcanzar la felicidad última, es necesario que para alcanzarla conozca qué es la felicidad, que establezca su fin y que este sea objeto de su atención; después, necesita conocer las cosas que le capacitan para alcanzar la felicidad y luego ha de hacerlas"31.

Hay una profunda implicación entre conocimiento y acción, entre saber teórico y saber práctico, al poner de manifiesto cómo el hombre debe conocer primeramente aquellas cosas por las que se consigue la felicidad y después realizarlas.

De cuanto se ha visto hasta ahora, se pueden señalar tres funciones propias del intelecto agente: la de dar formas ónticas al universo material; la de dar formas noéticas a la facultad racional humana, para actualizar el conocimiento del hombre; en tercer lugar, la de velar por la felicidad de éste ${ }^{32}$. Es justamente en esta tercera función donde entra en juego la razón práctica, de la que ahora hablaré.

30 Kitâb al-tanbîh 'alà sabîl al-sa'âda ("Información sobre el camino de la felicidad"), S. KHALIFAT (ed.), Amman: Publications of the University of Jordan 1987, p. 177.

31 Al-Fârâbî's The political Regime (Al-siyâsa..., p. 78; trad. esp.: AL-FÂRÂBî: Obras filosófico-politicas..., p. 47.

32 Hay una cuarta función, que no es del caso comentar aqui: se trata de la iluminación que el intelecto agente lleva a cabo sobre la potencialidad de la 


\section{La razón práctica y sus primeros principios}

La primera y gran división que Alfarabi establece en Las fuentes de las cuestiones entre las facultades racionales humanas es la de intelecto teórico e intelecto práctico, como se vio. De aquél sabemos que lo divide en diversos grados, estudiados con detalle en su Epistola sobre los sentido del "intelecto". Del práctico se ocupa en varias obras.

Alfarabi toma esta división de Aristóteles. He indicado antes el texto del De anima. En la Ética nicomáquea sostiene lo siguiente:

"Establecemos que son dos las partes racionales: una, con la que percibimos las clases de entes cuyos principios no pueden ser de otra manera, y otra, con la que percibimos los contingentes (...) A la primera vamos a llamarla científica y a la segunda, razonadora, ya que deliberar y razonar son lo mismo"33.

Los términos que utiliza Aristóteles para designar estas dos facultades intelectuales $o$ partes del alma racional son $\tau \delta$

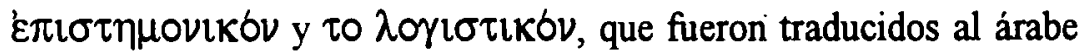

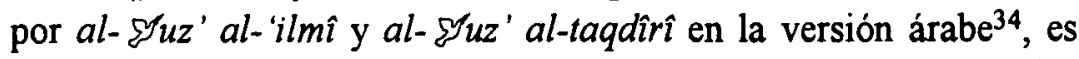
decir, "la parte científica" y "la parte estimativa", que no son los términos que utiliza Alfarabi. En el mismo libro y en el capitulo siguiente, Aristóteles distingue entre entendimiento práctico y

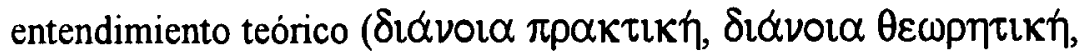
al-fikr al-'amalî, al-fikr al-ta'ammuli, "pensamiento práctico" y "pensamiento contemplativo")"35. Pero es quizá el texto de Politica donde Aristóteles propone con nitidez esta división: "Según acostumbramos a dividirla, la razón está escindida en dos; una es

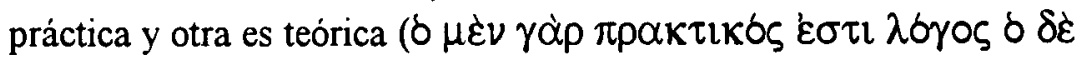

imaginación para producir el conocimiento profético, cfr. La recepción árabe del 'De anima', pp. 173-177.

33 ARISTÓteles: Et. Nic., V, 1, 1139a 6-14.

34 ARISTÛTẦî̀: Al-ajlâq, A. Badawi (ed.), Kuwait, 1979, p. 209.

35 ARISTÓTELEs: Et. Nic., VI, 2, 1139a 25-29; ed. árabe, p. 209. 
$\theta \varepsilon \omega \rho \eta \tau \iota \kappa \delta \zeta) " 36$. Sin embargo, no sabemos si Alfarabi llegó a conocer este texto en la obra de Aristóteles, pues desconocemos por ahora si llegó a ser traducido al árabe ${ }^{37}$.

Alfarabi define la razón práctica como la facultad por la que el hombre puede discernir aquellas cosas cuya naturaleza consiste en ser hechas por el hombre y cambiarlas de un estado a otro ${ }^{38}$. Son las cosas a las que Aristóteles llama "contingentes" ( $\tau \alpha \dot{\varepsilon} \varepsilon \nu \delta \varepsilon \chi 0 \mu \varepsilon v \alpha$ ), es decir, aquellas cosas que tienen la posibilidad de ser de otra manera, precisamente porque dependen de la voluntad del hombre. Alfarabi dice que Aristóteles 'ha llamado 'intelecto práctico' a la facultad que entiende, entre los seres, a aquellos que el hombre puede hacer existir en acto en las cosas naturales, pues al entender esa clase de seres le es útil el hacerlos existir"39.

La razón práctica, pues, tiene que ver con el quehacer del hombre: "la [facultad racional] práctica es aquella por la que se conoce todo aquello cuya naturaleza consiste en ser hecho por el hombre

${ }^{36}$ ARISTÓTELES: Politica, VII, 14, 1333a 25-26.

37 A falta de manuscritos conservados y de referencias precisas en los autores árabes, la opinión común entre los estudiosos es que no se realizó versión alguna de la Politica al árabe, por lo que permaneció desconocida en el mundo del islam. Sin embargo, si sabian que existia esta obra. S. Pines sospecha que pudo haber traducción parcial, paráfrasis o selección de extractos, cfr. S. PINes: "Un texte inconnu d'Aristote en version arabe", en AHDLMA 23 (1956), pp. 5-43; "La loi naturelle et la société: la doctrine politico-théologique d'Ibn Zur $\$ \$$ a, philosophe chrétien de Bagdad", en Scripta Hierosolymitana 9 (1961), pp. 154-190; "Aristotle's Politics in Arabic Philosiophy", en Israel Oriental Studies 5 (1975), pp. 150-160; ahora reunidos estos tres trabajos en The Collected Works of Shlomo Pines, vols. II y III, Jerusalén: The Hebrew University 1986-1996. Cfr. también R. BraguE: "Note sur la traduction arabe de la Politique, derechef, qu'elle n'existe pas", P. ALBENQUE (ed.): Aristote politique, Paris: PUF 1993, pp. 423-433.

38 Fusûl muntaza'a..., $\$ 7$, p. 29; trad. esp.: AL-FàrÀBî: Obras filosóficopoliticas..., p. 102.

${ }^{39}$ Falsafat Aristûtâlis, M. MAHDI (ed.), Beirut, 1961, p. 124; trad. ing. M. MAHD!: Alfarabi's Philosophy of Plato and Aristotle, Ithaca: Comell University Press 1969, p. 123. 
voluntariamente"40. "Por eso es necesario también investigar las acciones que proceden de la voluntad (al-irâda), la querencia ( $a$ l$m a$ i $\hat{i}^{\prime} a$ ) y el libre albedrío (al-ijtiyâr) que dependen del intelecto práctico. Estas constituyen la voluntad humana"41. Hay que conocer y estudiar las acciones humanas porque, a diferencia de los demás animales, son ellas, en tanto que proceden de la voluntad, las que ayudan al hombre a llegar a su perfección. Con ello, Alfarabi somete la razón práctica al servicio de la razón teórica, que es aquella que permite alcanzar la felicidad:"La razón (al-nátiqa) es en parte práctica y en parte teórica. La práctica está hecha para servir a la teórica, mientras que la teórica no está hecha para servir a ninguna otra, sino que por medio de ella se llega a la felicidad"42.

El quehacer del hombre es doble. Está orientado hacia la consecución de determinadas artes, útiles para la vida, o está encaminado a la realización de aquellas acciones que hacen al hombre virtuoso o que le llevan al vicio, esto es, tienen que ver con la felicidad. Alfarabi afirma que la facultad racional práctica es técnica (mihniyya) ${ }^{43}$ o deliberativa (fikriyya): "La técnica es aquella por la que se adquieren las artes y los oficios, mientras que la deliberativa es aquella por la que se considera y medita acerca de lo que se debe hacer o no hacer en cada asunto"44. La técnica o productiva depende también de la voluntad del hombre, que quiere hacer instrumentos para servirse de ellos y que crea las distintas artes técnicas. En su Catálogo de las ciencias, Alfarabi dice: "Unos cuerpos fisicos son artificiales (sináiyya) y otros naturales (tabî'iyya). Artificiales son, por ejemplo, el cristal, la espada, la cama, la tela y, en general, todo aquello que existe por el arte y por

\footnotetext{
40 Al-Fârâbî's The political Regime (Al-siyâsa..., p. 33; trad. esp.: AL-FÂRÂBî: Obras filosófico-políticas..., p. 8.

41 Falsafat Aristûtâlis..., p. 131; trad. ing. M. MAHDI: Alfarabi's Philosophy of Plato and Aristotle..., p. 129.

42 Madina al-fádila, p. 208; trad. cit., p. 72.

${ }^{43}$ El término mihna traduce a veces el griego $\tau \varepsilon \chi \chi \eta$.

44 Al-Fârâbî's The political Regime (Al-siyâsa..., p. 33; trad. esp.: AL-FÂRÂBî: Obras filosófico-politicas..., p. 8.
} 
voluntad del hombre"45. Y en los Artículos de la ciencia politica desarrolla un poco más la idea de estas dos facultades, la técnica y la deliberativa o cogitativa:

"La técnica y propia del arte es aquella por la que se adquieren las diversas técnicas, como, por ejemplo, la carpintería, la medicina y la náutica. La deliberativa es aquella por la que reflexionamos sobre lo que queremos hacer cuando queremos hacerlo, si es posible hacerlo o no y, si es posible, cómo se debe hacer esa acción" 46 .

Así, la función principal de la razón práctica es la deliberación, entendida como un proceso mental capaz de determinar los medios específicos y propios para alcanzar un fin, si son adecuados o no para ello. Esta función tiene diversos grados, según la excelencia en descubrir aquellos medios que llevarán a bienes excelentes, medios o supuestos. Es prudencia o sabiduría práctica (ta 'aqqul) cuando se delibera sobre las cosas que son más excelentes o mejores respecto de aquello que se hace para que el hombre adquiera un bien verdaderamente grande y un fin noble o virtuoso, sea la felicidad o algo indispensable para alcanzar la felicidad; es talento o sagacidad (kays) cuando se delibera sobre lo mejor y más capaz para alcanzar bienes menores; y, en fin, es astucia (dahâ') cuando se delibera sobre lo mejor y más excelente para alcanzar bienes supuestos, como riquezas o placeres ${ }^{47}$.

Este intelecto práctico se perfecciona con la experiencia y por medio de ella el hombre adquiere los primeros principios del obrar, semejantes a los primeros principios del conocer, pero diferentes de éstos en tanto que no son necesariamente universales:

45 Ihsâ' al- 'ulûm: Catálogo de las ciencias, A. GonzÁlez Palencia (ed. y trad.), Madrid-Granada: CSIC, $2^{a}$ ed., 1953, p. 77 del texto árabe, p. 55 de la traducción. 46 Fusûl muntaza'a..., \$7, pp. 29-30; trad. esp.: AL-FÂRÂBî: Obras filosóficopoliticas, p. 102.

47 Fusûl muntaza'a..., §39, pp. 55-56; trad. esp.: AL-FÂRÂBî: Obras filosóficopoliticas, p. 117. 
"El intelecto práctico es una facultad por la que de las múltiples experiencias de las cosas y de la prolongada observación de las cosas sensibles adquiere el hombre premisas por las que le es posible ocuparse de lo que conviene elegir o evitar en cada una de las cosas cuya acción nos compete. Algunas de estas premisas son universales, que contienen bajo cada una de ellas cosas que deben ser elegidas o evitadas, mientras que otras son singulares y particulares, que son usadas por el hombre como semejanzas de aquellas cosas que no ha podido observar y de las que quiere ocuparse. Este intelecto es sólo intelecto en potencia mientras la experiencia no se ha realizado; pero, cuando las experiencias se han dado y se han conservado, se convierte en intelecto en acto. Este intelecto que ya está en acto se acrecienta con el aumento de las experiencias durante cada una de las edades de la vida del hombre"48.

Proporciona, pues, premisas singulares sobre las que sólo pueden formarse silogismos singulares.

Que la razón práctica tiene primeros principios es algo que Alfarabi reconoce en varias obras. Asi, por ejemplo, en la Epistola sobre los sentidos de "intelecto", donde al señalar el cuarto significado dice lo siguiente:

"En cuanto al intelecto que menciona en el libro sexto de la Ética, [Aristóteles] quiere aludir con él a la parte del alma que adquiere, por perseverar en el hábito de alguna de las cosas que están en algún género y por la larga experiencia en algunas cosas que están en algún género y durante un largo tiempo, la certeza en los juicios y en las premisas referentes a las cosas propias de la voluntad, cuya condición es ser elegidas o ser evitadas. En el libro sexto de la Ética, [Aristóteles] llama intelecto a esta parte del alma. Los juicios que llegan al hombre de esta manera y en esa parte del alma

48 Fusûl muntaza'a..., §38, pp. 54-55; trad. esp.: AL-FâRÂBî: Obras filosóficopoliticas, pp. 116-117. 
son los principios del que se muestra inteligente en el obrar y del que es ingenioso, en aquello que ha de descubrirse respecto de aquellas cosas propias de la voluntad, cuya condición es ser elegidas o ser evitadas. La relación de estos juicios con aquello que se descubre por mostrarse inteligente en el obrar es como la relación de aquellos principios primeros, mencionados en el Libro de la demostración, con lo que se descubre con ellos. Así como aquéllos son principios para quienes practican las ciencias teóricas, con los cuales ellos descubren aquello que, respecto de las ciencias teóricas, hay que conocer, pero no hacer; así también, éstos son principios para el que se muestra inteligente en el obrar y para el ingenioso en lo que hay que descubrir respecto de las cosas propias de la voluntad y prácticas. Este intelecto, mencionado en el libro sexto de la Ética, crece con el hombre a lo largo de su vida; aquellos juicios se refuerzan en él y se le añaden en cada momento otros juicios que antes no poseía. Respecto a esta parte del alma que él ha llamado 'intelecto', los hombres se diferencian mucho entre sí. Aquel en quien estos juicios son perfectos en un cierto género de asuntos llega a ser de experta opinión en ese género. De experta opinión significa aquel al que, cuando aconseja sobre algo, se le acepta esa opinión suya sin exigirle una demostración sobre ello y sin preguntarle nada, pues son aceptadas las cosas que ha aconsejado, aunque no proporcione prueba alguna sobre ninguna de ellas. Por esta razón, es raro que un hombre llegue a poseer esta cualidad, a no ser cuando se hace viejo, porque esta parte del alma tiene necesidad de largas experiencias, que sólo suceden tras largo tiempo, para que se reafirmen en él aquellos juicios"49.

En La ciudad excelente expresa la existencia de estos primeros principios dados por el intelecto agente:

49 AL-FÂRÂBî: Risâla fî ma'anî..., pp. 9-11; trad. esp. R. Ramón GUERRERO: Contribución a la historia de la filosofia árabe..., pp. 409-413. 
"Los inteligibles primeros comunes [a todos los hombres] son de tres clases: 1) los principios de las artes prácticas (almihan al-'amaliyya); 2) los principios por los que se tiene conocimiento de lo bello y de lo feo (al-şamîl wal-qabîh) en las acciones del hombre; 3) los principios que son usados para conocer por medio de ellos los seres que no compete hacer al hombre, sus principios y sus rangos" $"$.

La razón práctica, pues, tiene primeros principios. Se desarrollan en ella a partir de la experiencia. Pero, para ello, necesita del intelecto agente.

\section{Intelecto agente y razón práctica}

Para Alfarabi hay analogía entre los primeros principios de la razón teórica, que, como para Aristóteles, se adquieren sin necesidad de reflexión o deliberación previa y que son premisas universales, verdaderas y necesarias ${ }^{51}$, y los primeros principios de la razón práctica. Sin embargo, esta analogía no es total y completa, pues no llega hasta el punto de que ambos tipos de principios se identifiquen en cuanto a su naturaleza, porque los principios de la razón práctica se obtienen por una larga experiencia durante la que se perfeccionan cada vez más, según se lee en el parágrafo 38 de los Fusûl.

Estos principios primeros o "inteligibles voluntarios", que pueden ser conceptos como "justicia" o proposiciones morales básicas, son únicos y universales, aunque sus atributos de aplicación - sus "accidentes y estados", como los llama Alfarabi - sean muchos y variables en cuanto al tiempo y al lugar ${ }^{52}$. Que son únicos $y$

${ }^{50}$ Madina al-fâdila, pp. 202-204; trad. cit., p. 70. Alonso traduce la primera clase de principios asi: "la primera contiene los principios de la geometria especulativa», según las lecturas que hacen otros manuscritos, seguidas por otros editores de la obra como Dieterici y Nader.

51 AL-FÂRÂBî: Risâla $f \hat{i}$ ma'ânî..., pp. 8-9; trad. esp.: R. Ramón GuERRERo: Contribución a la historia de la filosofia árabe..., pp. 407-409.

52 Cir. Th. A. DruarT: "Al-Fârâbî, Ethics, and First Intelligibles", en Documenti e Studi sulla tradizione filosofica medievale, 8(1997), p. 419. 
universales parece deducirse del siguiente texto en el que habla de los inteligibles voluntarios:

"Se ve claro esto en las cosas naturales, como 'hombre', pues cuando [este inteligible] existe en acto fuera del alma, los estados y accidentes que existen en él en un cierto momento son diferentes de los que tiene en otro momento posterior o anterior; lo mismo ocurre en lugares diferentes, pues los estados y accidentes que tiene cuando existe en un país son diferentes de los que tiene cuando existe en otro pais. En todos ellos, lo que es inteligido del sentido de 'hombre' es un sólo inteligible" 53 .

Los inteligibles permanecen aun cuando varien sus afecciones espaciales y temporales.

Que esos principios van acompañados de atributos mutables y variables lo afirma claramente:

"Los inteligibles voluntarios no pueden existir si no es junto con los [accidentes y estados] que los acompañan (..) Los estados y los accidentes (al-ahwâl wa-l-a'râd) cuya naturaleza consiste en acompañar [a los inteligibles voluntarios] son estados y accidentes que cambian siempre, aumentando o disminuyendo, y forman composiciones unos con otros sin poder ser abarcados por reglas formales variables e inmutables. Para algunos de ellos no se pueden establecer reglas; para otros se pueden establecer reglas, pero son reglas variables y máximas mutables" 54 .

Esta mutabilidad que se da en los principios prácticos, en tanto que sometidos a los cambios temporales y locales, es percibida por la facultad deliberativa de la razón práctica:

53 Tahsîl al-sa'âda ("La adquisición de la felicidad"), Y. A. YÂsM (ed.), AlFârâbî. Al-a'mâl al-falsafiyya, Beirut: Dar al-Manahil 1987, p. 147.

54 Tahsîl al-sa'âda ("La adquisición de la felicidad")..., pp. 145-146. 
"A estas cosas no las abarcan las ciencias teóricas, que sólo abarcan los inteligibles que en modo alguno cambian. Por eso es necesaria otra facultad y técnica ${ }^{55}$ por la que se disciernen las cosas inteligibles voluntarias en tanto que tienen accidentes mutables, que son los aspectos por los que se realizan como existentes en acto a partir de la voluntad en un tiempo determinado, en un lugar determinado y en un suceso determinado. La técnica y la facultad por la que se descubren y se disciernen los accidentes que son variables en los inteligibles cuyos casos particulares existen por la voluntad (...) es la facultad deliberativa (al-quwwa alfikriyya)" 56 .

Hay, entonces, en los principios de la razón práctica una cierta indeterminación, como ya señaló Aristóteles, provocada por el hecho de que estos principios sobre los que hemos de deliberar tienen que ver con lo que está en nuestro poder y es realizable: se delibera "acerca de cosas que suceden la mayoria de las veces de cierta manera, pero cuyo desenlace no es claro y de aquellas en que es indeterminado" 57 .

Estos principios son proposiciones a las que la razón no puede rehusar su asentimiento, bien porque son principios conocidos $y$ aceptados por todos o por la mayoria, o porque son principios que se alcanzan por la experiencia y la observación ${ }^{58}$. Sirven al hombre prudente para discernir las cosas que debe elegir y las que debe evitar con vistas a alcanzar su felicidad. Ésta es conocida por la razón teórica; la desiderativa o apetitiva quiere alcanzarla y la deliberativa o cogitativa reflexiona sobre el modo de alcanzarla:

\footnotetext{
${ }^{55}$ Aqui leo mihna, la variante de otros mss., señalada por el editor en nota. Éste, sin embargo, ha preferido leer mâhiyya, "esencia".

56 Tahsîl al-sa'âda ("La adquisición de la felicidad")..., pp. 149-150.

57 ARISTÓTELES: Et. Nic., III, 3, 1112b 7-9.

58 Cfr. Fusûl muntaza'a..., §46; trad. esp.: AL-FÂRÂBî: Obras filosóficopoliticas..., p. 119.
} 
"La felicidad, que sólo el hombre puede entender y percibir, es conocida por la facultad racional teórica y no por ninguna de las otras facultades; la conoce cuando utiliza los primeros principios y conocimientos, que el intelecto agente le da. Cuando la conoce, entonces la desea por la facultad apetitiva; luego reflexiona por medio de la facultad racional práctica sobre lo que debe hacer para alcanzarla y hace aquellas acciones, que ha descubierto por la reflexión, con los instrumentos de la facultad apetitiva. Las facultades imaginativa y sensitiva auxilian y obedecen a la racional y le ayudan a incitar al hombre a hacer las acciones por las que obtiene la felicidad; entonces, todo aquello que surge del hombre será bueno. De esta única manera surge el bien voluntario"s9.

Todas las facultades del alma están, pues, implicadas en la consecución de la felicidad. La sabiduría como virtud del intelecto teórico conociendo la verdadera felicidad y la sabiduría práctica o prudencia como virtud de la razón práctica ocupándose de lo que hay que hacer para alcanzarla, "colaboran mutuamente en el perfeccionamiento del hombre, de manera que la sabiduria es la que da el fin último y la prudencia da aquello con lo que se obtiene ese fin"60. Esta mutua colaboración de todas las facultades garantiza la unidad del alma.

Pero es el intelecto agente el que tiene que ver con la felicidad humana, porque los primeros principios proceden en definitiva de él:

"Puesto que el objetivo por el que existe el hombre es alcanzar la felicidad, que es la perfección última que permanece como aquello dable a los seres posibles capaces de recibirlo, es preciso decir la manera por la que el hombre puede llegar a esta felicidad. Sólo puede hacerlo cuando, en

59 Al-Fârâbî's The political Regime (Al-siyâsa ..., p. 73; trad. esp.: AL-FÂRÂBî: Obras filosófico-politicas..., p. 44.

${ }^{60}$ Fusûl muntaza 'a ..., p. 62; trad. esp.: AL-FÂRÂBî: Obras filosófico-politicas ..., p. 120. 
primer lugar, el intelecto agente le ha dado los primeros inteligibles, que son los primeros conocimientos. Pero no todo hombre está preparado por naturaleza para recibir los primeros inteligibles, porque los individuos humanos han sido creados por naturaleza con facultades diferentes y con distintas disposiciones. Unos no puede recibir por naturaleza ninguno de los inteligibles primeros; otros pueden recibirlos, pero de forma distinta, como los locos; otros, en fin, pueden recibirlos tal como son. Éstos son quienes tienen una naturaleza humana sana y es propio de ellos, y no de los otros, poder obtener la felicidad. Los hombres que disponen de una naturaleza sana tienen una disposición innata común por la que están preparados para recibir inteligibles comunes a todos, por los que tienden hacia asuntos y acciones comunes a ellos. Pero después de eso, se diferencian y se distinguen unos de otros, pues tienen naturalezas que son propias de cada uno y de cada grupo"61.

El intelecto agente es el que proporciona unos primeros principios prácticos, que no son adquiridos porque no dependen de la experiencia. Ya he citado el texto de La ciudad excelente donde lo dice con toda claridad: de los tres tipos de principios que expone, la segunda clase, es decir, aquellos por los que se conocen las acciones bellas y feas, buenas y malas de los hombres, son los que competen a la sabiduria práctica, que es la virtud principal de la razón práctica.

En su Información sobre el camino de la felicidad, Alfarabi determina abiertamente a qué tipos de primeros principios de la razón práctica se refiere. Cuando habla de la excelencia del discernimiento nos dice:

"La excelencia del discernimiento es aquello por lo que obtenemos y adquirimos los conocimientos de todas las cosas que el hombre ha de conocer. Ellas son de dos clases: aquello cuya naturaleza es ser conocido y que no puede ser

${ }^{61}$ Al-Fârâbî's The political Regime (Al-siyâsa..., p. 74-75; trad. esp.: AL-FÂRÂBî: Obras filosófico-politicas..., p. 45. 
hecho por el hombre, sino sólo conocido, como el conocimiento que tenemos de que el mundo es creado, que Dios es uno o que hay muchas causas de las cosas sensibles; $y$, segundo, aquello cuya naturaleza es ser conocido y hecho, como nuestro conocimiento de que la piedad filial es buena, la traición es mala y la justicia es bella"62.

Estas proposiciones, que son juicios de valor con carácter universal y necesario, corresponden a los "universales de la filosofia práctica", bajo los cuales caen todas las leyes religiosas excelentes o virtuosas, de los que habla en el Libro de la religión ${ }^{63}$. Son los "conocimientos primeros de la ciencia práctica"64, capaces de fundar una ciencia demostrativa, según lo que puede deducirse de las siguientes palabras:

"(...) la ciencia que contiene los universales es la que proporciona las causas de los particulares que están subordinados a ella. La parte práctica de la filosofía es, por tanto, la que proporciona las causas de las reglas por las que se determinan las acciones, en razón de qué se establezca como condición y de cuál sea el objetivo que se intenta lograr por esas reglas. Y como la ciencia de algo consiste en el conocimiento demostrativo, esta parte de la filosofia es la que proporciona entonces la demostración de las acciones determinadas que hay en la religión virtuosa"65.

Así, la filosofia práctica es llamada "ciencia" que "proporciona la demostración", es decir, es un saber, propiciado por la razón práctica y basado en principios primeros que proporciona el intelecto agente, que reúne las exigencias para que la ética sea entendida como

${ }^{62}$ Kitâb al-tanbîh 'alà sabill al-sa'âda, AL-FÂRÂBî (ed.): Al-a'mâl al-falsafîyya, pp. 253-254; trad. fran.: D. MALlET: "Le rappel de la voie à suivre por parvenir au Bonheur", en Bulletin d'Études Orientales, 39-40 (1987-1988), pp. 133-134.

${ }^{63}$ Kitâb al-milla wa-nusûs ujrâ, M. Mahdi (ed.), Beirut: Dar el-Machreq 1968, p. 47; trad. esp.: Obras filosófico-politicas..., p. 78.

${ }^{64}$ Falsafat Aristûtalis..., p. 62; trad. ing. M. MAHDI: Alfarabi's Philosophy of Plato and Aristotle ..., p. 74.

${ }^{65}$ Milla, p. 47; trad. cit., p. 78. 
verdaderamente científica ${ }^{66}$. La acción del intelecto agente, pues, se ejerce también sobre la razón práctica del hombre.

${ }^{66}$ Desarrolla esta idea con amplitud Th. A. DRUART: "Al-Fârâbî, Ethics..., pp. 405408 . 
Copyright of Tópicos. Revista de Filosofía is the property of Universidad Panamericana and its content may not be copied or emailed to multiple sites or posted to a listserv without the copyright holder's express written permission. However, users may print, download, or email articles for individual use. 